\title{
Influence of hydrothermal ageing on single lap bonded CFRP joints
}

\author{
Costanzo Bellini, Gianluca Parodo, Wilma Polini, Luca Sorrentino \\ University of Cassino and Southern Lazio, Cassino (FR), Italy \\ gianluca.parodo@unicas.it
}

\begin{abstract}
Nowadays adhesives are widely used in structural applications, in particular for assembly composite materials. In fact, this technique allows to obtain a more uniform load in the joint, to realize a joint with a higher specific strength and to avoid drilling parts as in the case of bolted joints. However, the mechanical properties of bonded parts over time are not well understood if they are subjected to a more or less aggressive environment. Generally, the main factors of influence regarding the durability of bonded joints are humidity and temperature, but their effects are not always clear if these two factors act simultaneously. In this work the effect of hydrothermal ageing on the mechanical resistance of single lap bonded CFRP joints has been investigated. In particular two types of adhesives (AF 163-2K film and EA 9309NA paste) and three ageing environments (thermal cycles from $-28^{\circ} \mathrm{C}$ to $85^{\circ} \mathrm{C}$ in air, distilled water and salt water) have been chosen for the activity.
\end{abstract}

KEYWORDS. Hydrothermal ageing; Adhesive bonding; Single lap joint; Experimental tests.

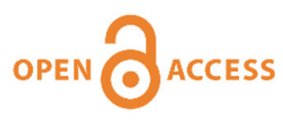

Citation: Bellini, C., Parodo, G., Polini, W., Sorrentino, L., Influence of hydrothermal ageing on single lap bonded CFRP joints, Frattura ed Integrità Strutturale, 45 (2018) $173-182$.

Received: 02.06 .2018

Accepted: 23.06.2018

Published: 01.07.2018

Copyright: (C) 2018 This is an open access article under the terms of the CC-BY 4.0, which permits unrestricted use, distribution, and reproduction in any medium, provided the original author and source are credited.

\section{INTRODUCTION}

I $\mathrm{n}$ the last decades, there has been an increasing use of composite materials in structural applications. This has entailed greater attentions from the designers regarding the stability of the composite structures in the medium-long term, in particular on the weak points of the structures, namely in the junctions between the components of the assembly. The composite parts can be assembled using rivets or bolts, or adhesives or, in the most complex joints, through a combination of both. Compared to traditional fastening systems, the use of structural adhesives allows to obtain a series of advantages such as the reduction of the weight of the joints, the elimination of corrosive problems typical of metal rivets and bolts and the reduction of the local delamination of the parts due to drilling, as noted by Sorrentino et al. [1,2]. However, nowadays their use is limited by the incomplete knowledge of how they can behave over time in contact with more or less aggressive environments. For example in the case of epoxy adhesives, it is known that the factors of influence of the stability of the joint over time are mainly the temperature and humidity, but in most cases, it is impossible to estimate their effect on the durability of the joint except by experiments. In fact, it is difficult to reach definitive conclusions because of the various possible combinations adherend/adhesive. The knowledge of the behavior of the individual adherend and adhesive is not a sufficient condition to estimate the strength of the assembled joint. An example is the case of hybrid composite-metal coupling, which can lead to corrosion phenomena. In seawater, the galvanic coupling due to the different nature of the 
adherends not only causes the onset of corrosive phenomena on the metallic adherend, but can also lead to forms of damage in composite adherend like bubbles and swellings, as noted by Tucker et al. [3]. Moreover, adherend in composite material possess carbon fibres that are electrochemically nobler than most metals, so it is able to behave like a cathode. Consequently, it is possible the formation of a more aggressive environment localized at the fibre-matrix interface.

Both in steam and in liquid form, water is one of the most aggressive environments for bonded joints. Being the most widespread substance in the entire globe, the study of its influence on the degradation of the joint is fundamental in every type of application. This peculiarity generally derives from the presence of polar groups in the adhesives, which make the bonding intrinsically hydrophilic. Bowditch [4] has observed that the addition of silicon in the adhesive can decrease the amount of mechanical degradation due to immersion in water for a certain period: the adhesive becomes more stable in water. He also states that increasing the test temperature to accelerate itself can be misleading because it is easy to analyze different damage mechanisms in this way. In fact, often the aggressiveness of the test environment is increased (for example by raising the temperature, increasing the humidity or simply varying the chemical composition), in order to reduce the test time and often neglecting the true phenomena that would occur in the real case. Furthermore, degradation can be exacerbated by the simultaneous presence of a load.

Armstrong [5,6] has studied the durability in distilled water of bonded joints realized with aluminum adherends combined with various types of epoxy adhesives. Specifically, he observed that the degradation is directly proportional to the diffusibility and the solubility of the water in the adhesive. Gravimetric analyses are generally used to measure the water absorbed by the joints. He noted that the saturation of water in epoxy adhesives is shown by an increase in weight that can vary from $0.5 \%$ to $13 \%$.

The temperature is able to accelerate the diffusion process. Wylde and Spelt [7] have analyzed the effects of temperature on water diffusion in epoxy adhesives, observing that the saturation condition is a function of temperature as long as it is below the Tg. Obviously the different nature of the adhesives does not make it possible to generalize the observations made only on specific tests. Wilken et al. [8] have experimentally observed that the presence of an interface between adherend and adhesive amplifies the diffusive phenomenon. Specifically, the diffusion that experimentally observed at the interface of the bonded joints appeared to be about 6 times greater than that observed in the bulk of the adhesive.

The molecular structure of an epoxy resin or epoxide-based materials may undergo physical changes caused by exposure at temperatures below the $\mathrm{Tg}$ for very long periods. These changes are manifested as the reduction of the free volume and the variation of molecular configuration, phenomena able to influence the reliability of components made with this type of resin. Odegard [9] describes these physical changes occurring in the molecular structure of the epoxy, investigating how they affect the properties of bulk.

Degradation of the epoxy resin in water can also lead to irreversible damage, not negligible in case of structural components. In their work, Zhou et al. [10] have observed that a composite laminate immersed in water for a sufficiently long time may show a partial dissolution of the matrix, observable only by gravimetric analysis. The diffusion of water in the degraded laminate leads to a behavior of the laminate that cannot be described by Fick's law. According to Zhou, this occurs only if the ratio between the temperature and the glass transition temperature exceed the nominal value of 0,25 . Still in the same work, Zhou et al. have noted that the expansion due to the absorption of water is much more limited in the direction of the fibres respect the others. Zanni et al. [11] have analyzed the diffusion of water in epoxy adhesives. They noted that the diffusivity is related to the temperature according to Arrhenius law and that the elastic modulus of the adhesive decreases as the diffusion phenomenon progresses. Furthermore, they hypothesize the existence of a phenomenon called capillary diffusion: the presence of surface tension relative to the adhesive-adherend interface leads to an increase in the driving force of water penetration into the joint. Epoxy adhesives are one of the most commonly used adhesive types for bonding composite materials. More recently, McConnell et al. [12] carried out dielectric studies on the effects of freezing and hydrolytic ageing on bonded joints in composite material realized with this type of adhesive. Using gravimetric analysis, they observed that the composite adherends have a water diffusion coefficient that is one order of magnitude higher respect the adhesive and that the freezing causes an increase in voids and micro-cracks in the adhesive itself. Furthermore, the presence of water in the adhesive affects the mechanical resistance of the same in an inversely proportional manner.

The research presented in this work is part of an experimental campaign on composite-composite single lap joints. In the previous work of the authors [13], the influence of the surface treatment of the adherends on the mechanical strength of the joint was analyzed. The need to achieve reliable bonding in the long term has led the scientific community to investigate the effect of humidity or temperature on bonded joints, but the results obtained are not always clear if these two factors act simultaneously. The study of the combined effect of hydrothermal ageing and operating temperature on the strength of the bonded joint is a topic that still needs further investigation. The objective of this second experimental phase is essentially to evaluate how the bonded joint, made of CFRP and epoxy adhesives, reacts to ageing induced by hydrothermal stress. To obtain a uniform and repeatable bonding surface, all the adherends have been realized with peel ply treatment. 


\section{MATERIALS AND METHODS}

$\mathrm{S}$ ingle lap joints were obtained from two laminates measuring $25.4 \mathrm{~mm} \times 101.6 \mathrm{~mm} \times 2.5 \mathrm{~mm}$ while, in order to have a square bonding area, the overlap length was placed at $25.4 \mathrm{~mm}$. All the specimens are realized according to ASTM D5868 and ASTM D1002. The nominal thickness of the adhesive was set equal to $0.76 \mathrm{~mm}$ (Fig. 1).

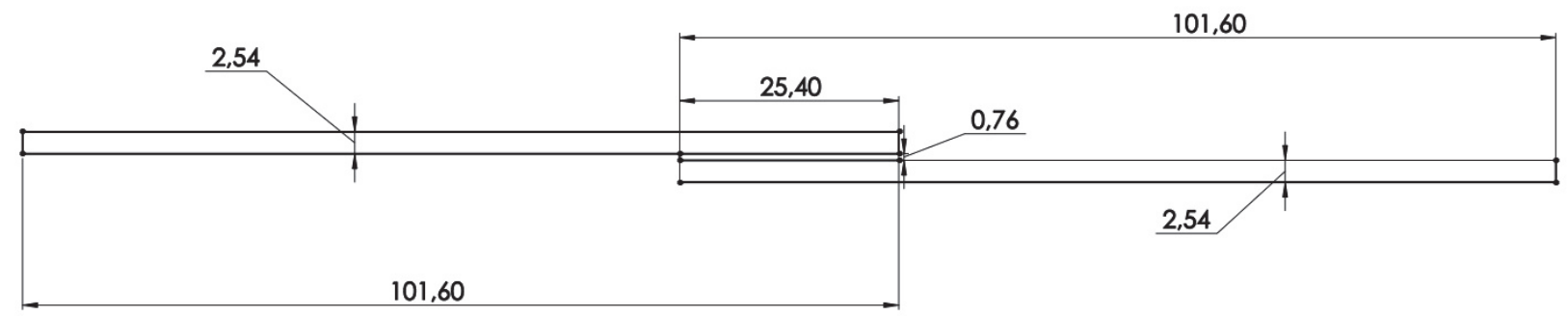

Figure 1: Measures of a single lap joint specimen.

A prepreg produced by SAATI S.p.A., made of ER450 epoxy resin and CC289 carbon fibres with 5H satin weave, was used for the realization of the adherends. The layup used was $\left[\left(0^{\circ}, 90^{\circ}\right)\right] 8$, where $\left(0^{\circ}, 90^{\circ}\right)$ is one layer of fabric. The treatment process consists of a ramp of $2^{\circ} \mathrm{C} / \mathrm{min}$. for $55 \mathrm{~min}$. and in maintenance at $135^{\circ} \mathrm{C}$ for 2 hours at a pressure of seven bar.

The peel ply used is 51789 produced by Precision Fabric Group, made of nylon fibres woven together. The operations carried out to obtain the surface finish simply consist of inserting it at the end of stratification on the laminate and removing it at the end of the polymerization just before the bonding phase.

The adhesives identified to perform the tests are the EA 9309NA paste adhesive produced by Hysol and the AF 163-2K film adhesive produced by 3M Scotch-Weld. The general characteristics of the adhesives are reported in Tab. 1.

\begin{tabular}{ccccccc}
\hline & Type & $\begin{array}{c}\text { Shear Strength [MPa] } \\
\text { ASTM D1002 }\end{array}$ & $\begin{array}{c}\text { Poisson's } \\
\text { Coefficient }\end{array}$ & $\begin{array}{c}\text { Tensile Strength } \\
\left(25^{\circ} \mathrm{C}\right)[\mathrm{MPa}] \\
\text { ASTM D638 }\end{array}$ & $\begin{array}{c}\text { Tensile Modulus } \\
\left(25^{\circ} \mathrm{C}\right)[\mathrm{MPa}] \\
\text { ASTM D638 }\end{array}$ & $\begin{array}{c}\mathrm{T}_{\mathrm{g}} \\
(\mathrm{Dry}) \\
{\left[{ }^{\circ} \mathrm{C}\right]}\end{array}$ \\
AF 163-2K & Film & 39.9 & 0.34 & 48.26 & 1103.2 & 108 \\
EA 9309NA & Paste & 34.5 & 0.35 & 37.90 & 2067.0 & 59 \\
\hline
\end{tabular}

Table 1: Properties of the adhesives.

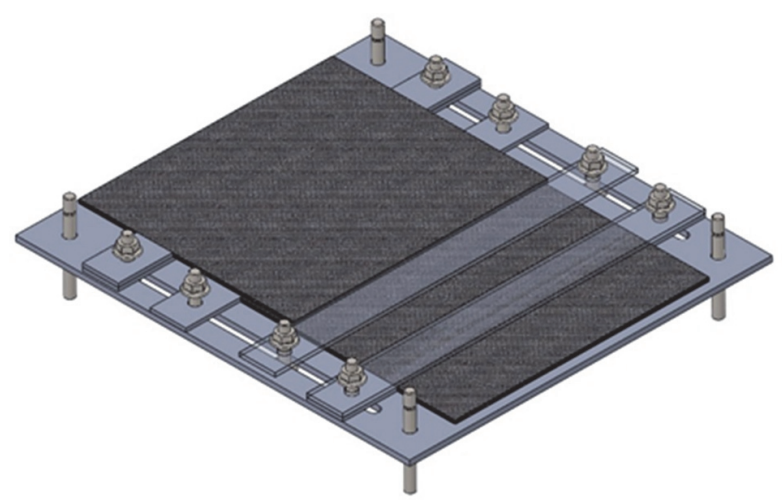

Figure 2: CAD of the mold used to realize SLJ specimens.

The Hysol EA 9309NA is a two-component paste adhesive, composed of a translucent beige paste (part A) and a red activator (part B), to be mixed according to the weight ratio of respectively 100 (part A) and 23 (part B). For this adhesive, the polymerization reaction takes place at room temperature for 7 days. 
The AF $163-2 \mathrm{~K}$ is a film adhesive with a thickness of about $0.24 \mathrm{~mm}$ and has a carrier inside which gives it greater tensile strength. The polymerization reaction occurs in an autoclave according to the technical data sheet.

In order to guarantee the final geometry of the joints, specific equipment for the bonding was used (Fig.2).

In total, 18 specimens were made, which were divided into 6 lots respectively, each consisting of 3 specimens. The 6 lots were randomly divided into three groups, so that each group has the same number of joints made with AF 163-2K and EA 9309NA. Subsequently, the created groups, made up of six specimens each, were subject to different cyclical conditions of ageing (Tab. 2).

\begin{tabular}{ccc}
\hline Factors & \# Level & Levels \\
\hline Adhesive & 2 & AF 163-2K, EA 9309NA \\
Ageing conditions & 3 & Distilled water, salt water, air \\
Replications & 3 & \\
\hline
\end{tabular}

Table 2: Experimental Plan.

To realize the ageing treatments, it has been used a model 125/45HA oven manufactured by Nabertherm GmbH, equipped with a convection chamber; and a 2700 model multimeter manufactured by Keithley Instruments, combined with the use of K-type thermocouples for temperature control during the process;

The specimens relative to the first group were subjected to a daily cycle of 4 hours at $85^{\circ} \mathrm{C}$ and about 20 hours at $-28{ }^{\circ} \mathrm{C}$. The specimens of the second group were immersed in distilled water. In order to avoid evaporation of the water, which would cause the rise of the specimens from the water itself, the container was closed with a nylon film called elastomax produced by Aerovac Systems Ltd. The specimens relating to the third group underwent the same process applied to the second group, using salt water instead of distilled water. The saline solution was made according to ASTM D1183. The latter groups were subjected to a daily freezing cycle at $-28^{\circ} \mathrm{C}$ for 16 hours and thawing and maintaining at $85^{\circ} \mathrm{C}$ for 6 hours. The remaining 2 hours were used to cool the containers to an acceptable temperature in order to place them in the climatic chamber. At the end of each cycle, a check on the water level in the containers was performed and, where necessary, a topup was carried out.

In order to monitor the temperature, a laminate of the same thickness of the adherends was inserted into each group with a K-type thermocouple inside. All three groups have undergone the above-mentioned cycles for thirty days.

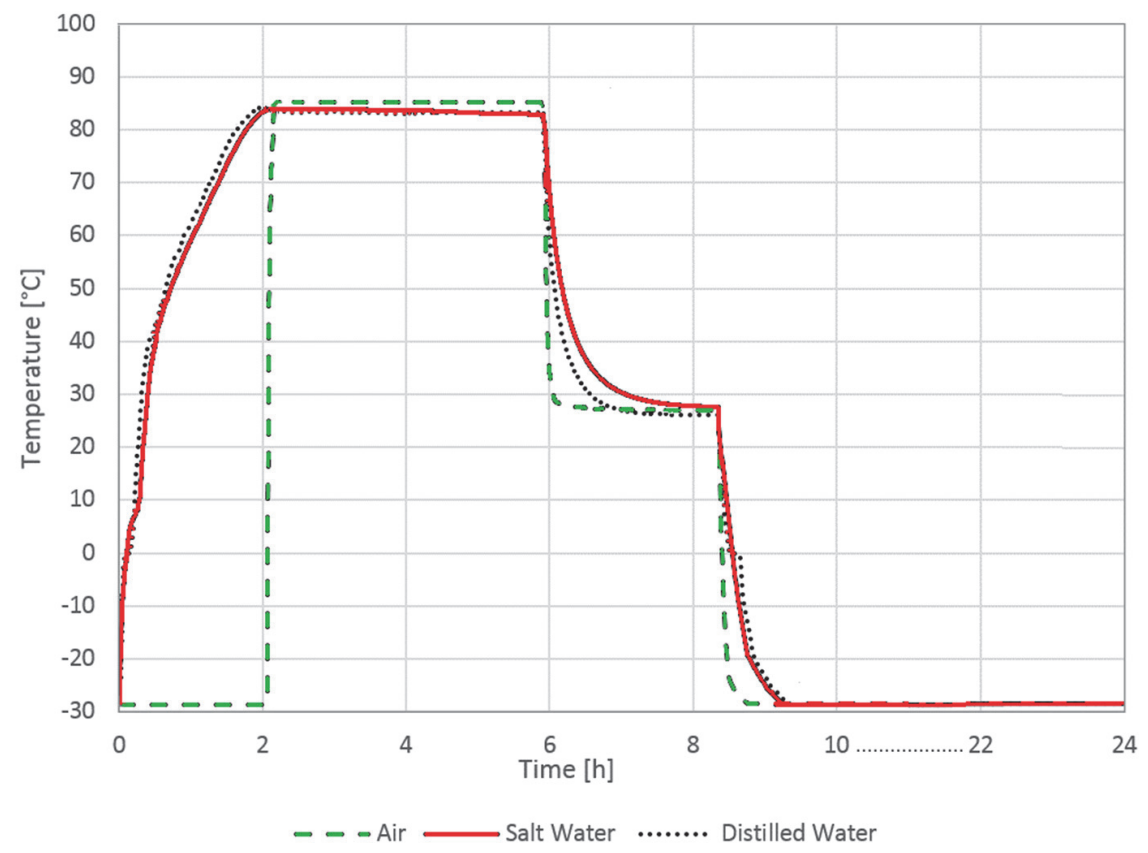

Figure 3: Ageing cycles measured with K-thermocouple. 
Fig. 3 shows the trend of the temperatures in the respective environment of the three groups. The heating transient for the two groups in water was completed within two hours. Subsequently, the group aged in air was placed in the oven and, having a much lower thermal inertia, reaches the operating temperature within a few minutes. Even in the cooling phase, the different thermal inertia between the three groups involves different cooling speeds: specifically, the cooling rate of the samples in air was an order of magnitude higher than the cooling speed of the samples in water.

Once the ageing phase was completed, the specimens were removed from the containers and left to dry at room temperature for one week; then they were tested.

The test conditions were performed according to ASTM D5868 using an INSTRON 5586 with a maximum capacity of $300 \mathrm{kN}$ and setting a crosshead speed of $1.3 \mathrm{~mm} / \mathrm{min}$.

\section{RESULTS AND DISCUSSIONS}

he reference values of failure loads for the unaged adhesives are taken from a previous work of the authors [13]. The results obtained from the lap shear tests are reported in Fig. 4.

For the purpose of being able to state if there are significant differences between the results obtained when the selected factors are changed, an analysis of variance was performed on the entire population of specimens produced. The results are reported in Tab. 3 .

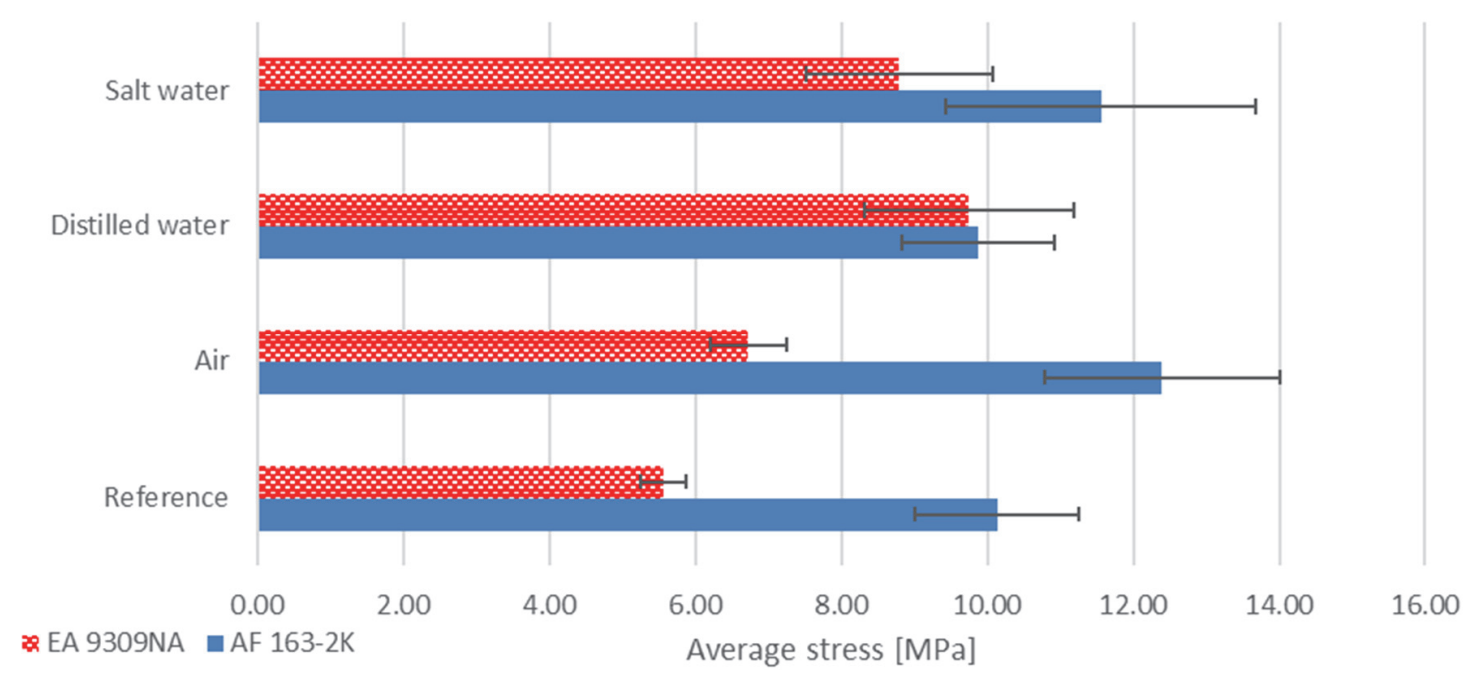

Figure 4: Results of the lap shear tests on the single lap joints.

\begin{tabular}{|c|c|c|c|c|}
\hline Source & Contribution & Mean Square & F-value & P-value \\
\hline Adhesive & $49.94 \%$ & 71.817 & 48.33 & 0.000 \\
\hline Ageing & $15.91 \%$ & 8.932 & 6.01 & 0.004 \\
\hline Interaction (Adhesive*Ageing) & $16.5 \%$ & 9.263 & 6.23 & 0.004 \\
\hline Residual & $17.65 \%$ & 1.486 & & \\
\hline
\end{tabular}

Table 3: Analysis of Variance: results obtained from all the specimens tested.

The p-values below 0.05 indicate that there are significant differences between the results obtained with the related factor. Therefore, it is possible to observe that the factor most characterizing the resistance of the joint is the type of adhesive: it has a greater influence on the process, which can be estimated through the contribution value of $49.94 \%$.

From the analysis carried out, ageing generally results in a very low influence $(15.91 \%$ contribution) on the strength of the bonded joint. However, the complexity of the experimental campaign does not allow to be able to give conclusions about 
the influence of ageing simply considering a global ANOVA, but requires analysis of one-way variances by fixing the type of adhesive.

\section{AF $163-2 K$}

From a visual analysis of the results related to the joints made with the AF 163-2K adhesive (Tab. 4), it is possible to state that the resistance values are very close to the reference value regardless of ageing. Therefore the ageing cycles did not produce deleterious effects for this type of adhesive. The statistical variability observed for this type of adhesive is probably due to the autoclave process. In fact, this process may results in a misalignment able to affect the mechanical characteristics of the joint, but it does not influence the adhesive decay.

The failure modes that show these specimens are all of the Light-Fibre-Tear type, according to ASTM D5573, as shown in Fig. 5. The high glass transition temperature of the adhesive probably gave greater stability to the maximum temperatures reached during ageing.

\begin{tabular}{ccccc}
\hline Source & Contribution & Mean Square & F-value & P-value \\
Ageing & $39.56 \%$ & 4.672 & 2.18 & 0.153 \\
Error & $60.44 \%$ & 2.141 & & \\
Total & $100.00 \%$ & & & \\
\hline
\end{tabular}

Table 4: One-Way ANOVA for AF 163-2K.

a

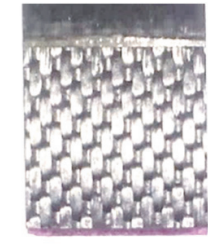

$\mathrm{C}$

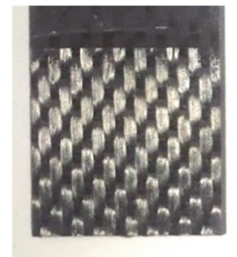

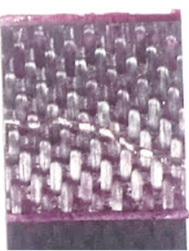

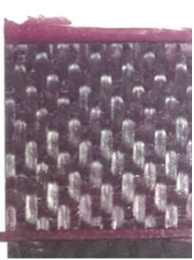

$\mathrm{b}$

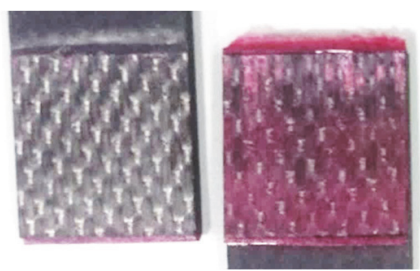

$\mathrm{d}$

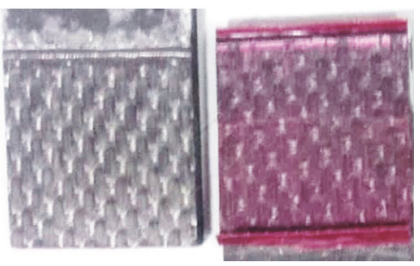

Figure 5: Failure surfaces of AF 163-2K specimens: a) without ageing; b) with air ageing; c) with distilled water ageing; d) with salt water ageing.

\section{EA 9309NA}

In the case of paste adhesive EA 9309NA (Fig. 4 and Tab. 5), it is possible to state that the behavior of the specimens has been heavily influenced by the ageing conditions, showing variable failure morphologies depending on the type of ageing. Joints aged in water undergo a strong increase in performance, achieving average performances of about $75 \%$ higher than the reference ones; also for samples aged in the air there is an increase in performance (due to a post-cure effect induced by the maximum temperature reached during ageing) but less significant (about 35\%). Probably in this group of specimens, the effects of damage due to the thermal shock suffered during the transient from $-28^{\circ} \mathrm{C}$ to $85^{\circ} \mathrm{C}$ of the duration of few minutes have taken place, while the specimens aged in water have undergone a softer transient lasting about 2 hours. Furthermore, this difference between the two groups can be due to a greater ductility and lower mechanical resistance of the edges of the adhesive due to degradation in the water-aged specimens, which may have resulted in an increase of the 
apparent resistance of the aged joints than the non-degraded joints. Chadegani et al. [14] and Kumar et al. [15] state that the stress field that is generated inside a single-lap joint has a singularity to the adhesive/adherend interface near the extreme edges, so that the ends of the bonding tend to be stressed more respect the central area of the interface. A greater ductility of the adhesive localized to the extremes allows to attenuate the presence of this singularity and in this way generate a more uniform load, allowing an increase in the apparent resistance of the joint, as noted by da Silva et al. [16]. It is possible to observe the chromatic variation on the green that occurs in the joints aged in water (Fig. 6c and Fig. 6d) compared to the other joints tested (Fig. 6a and Fig. 6b), which tends to concentrate near the edges of the bonding area. From the analysis of the failure surfaces, it is possible to observe how the failure mode passes from adhesive (Fig. 6a) to mixed adhesive/light fibre tear (Fig. 6b, Fig. 6c and Fig. 6d): this is probably due to an improvement of the resistance of the adhesive/adherend interface due to ageing.

\begin{tabular}{|c|c|c|c|c|}
\hline Source & Contribution & Mean Square & F-value & $\mathrm{P}$-value \\
\hline Ageing & $83.00 \%$ & 13.52 & 16.28 & 0.000 \\
\hline Error & $17.00 \%$ & 0.83 & & \\
\hline Total & $100.00 \%$ & & & \\
\hline
\end{tabular}

Table 5: One-Way ANOVA for EA 9309NA.

a
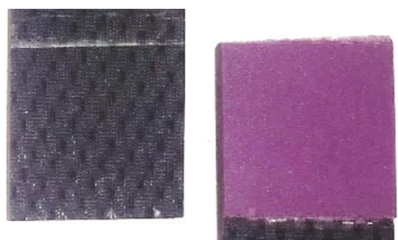

C

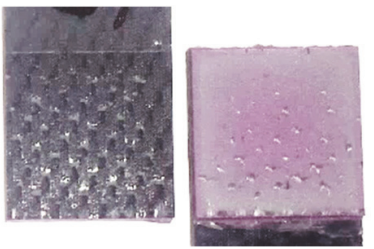

b

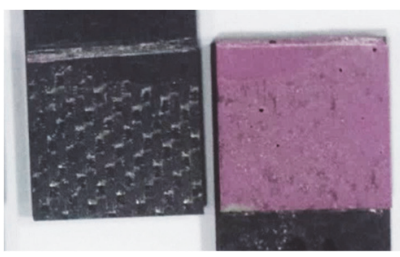

d

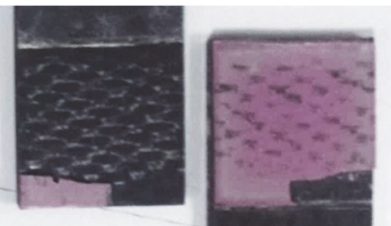

Figure6: Failure surfaces of EA 9309NA specimens: a) without ageing; b) with air ageing; c) with distilled water ageing; d) with salt water ageing.

The results of lap shear test obtained with EA 9309NA have shown a strong influence from ageing. DSC analyses were carried out to analyze how much the ageing has influenced the properties of the adhesive. The heating ramp used is $10^{\circ} \mathrm{C} / \mathrm{min}$. and the observation temperature range is from $25^{\circ} \mathrm{C}$ to $145^{\circ} \mathrm{C}$.

It is possible to state that, observing the curve relative to the unaged reference (Fig. 7), the polymerization at room temperature does not allow the total cure of the adhesive. In fact, the transition temperature is equal to $59^{\circ} \mathrm{C}$, according to the technical data sheet, and it presents an endothermic peak probably due to some unreacted components.

To be noted that there is no sensible difference between the behavior of the edge and the bulk of the bonded area of the adhesive.

By analyzing the results obtained on specimens aged in air (Fig. 8), the adhesive no longer presents an endothermic peak. This probably occurs because this treatment has entailed a complete polymerization of the adhesive: in fact, the lack of peaks is compatible with a post-cure effect of the ageing.

The DSC analysis of the samples tested in water showed that there are different behavior between the edge and the bulk of the adhesive. In particular, the edge of the adhesive (Fig. 9, curve A) presents an endothermic peak similar to unaged specimens, while the bulk of the adhesive (Fig. 9, curve B) does not present peaks. The adhesive has absorbed water only in the edges and probably this did not allow cross-linking of unreacted components during maintenance at the higher 
temperatures of the ageing cycle. This phenomenon appears only on the edge of the adhesive because the duration of the ageing treatment was too short to allow a uniform diffusion of water in the entire adhesive.

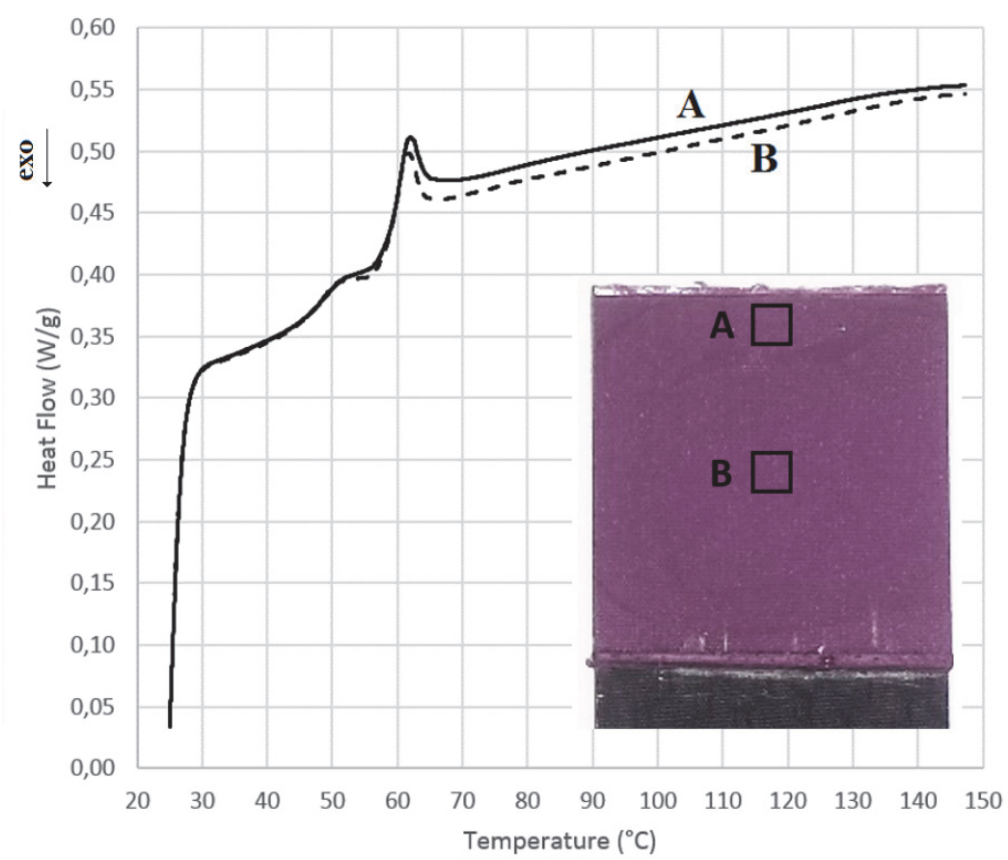

Figure7: DSC results from EA 9309NA unaged specimen.

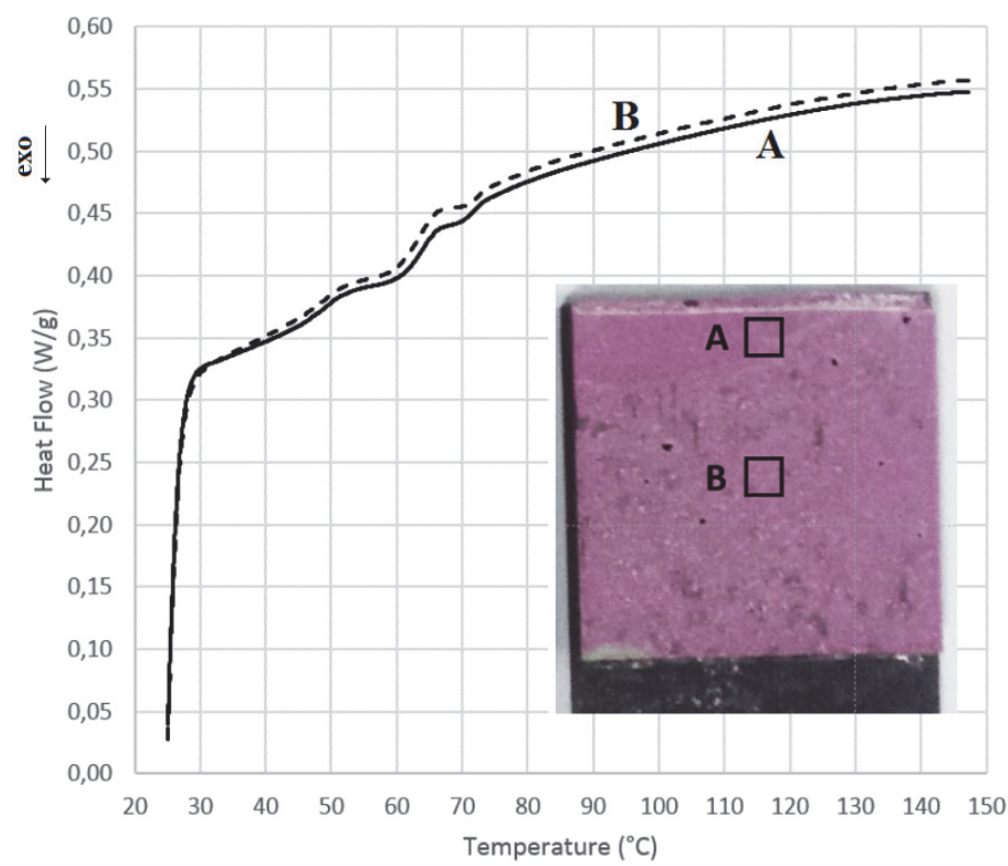

Figure 8: DSC results from EA 9309NA specimen aged in air.

The specimens aged in salt water showed an intermediate behavior between those aged in distilled water and those aged in the air. This result may be due to a greater difficulty of salt water to penetrate into the adhesive. 


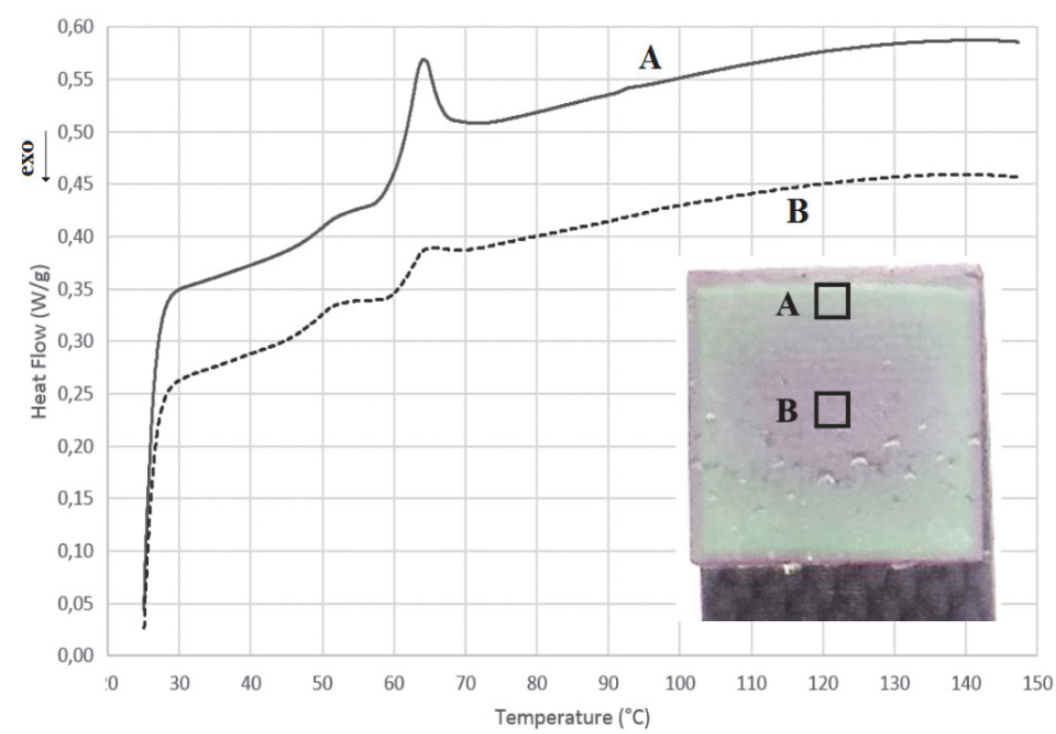

Figure 9: DSC results from EA 9309NA specimen aged in distilled water.

\section{COMPARISON BETWEEN AF 163-2K AND EA 9309NA}

A nalysing the results, it is evident that the ageing conditions have different effects on the two adhesives analyzed. In particular, the AF 163-2K shows greater stability in water than the EA 9309NA. Armstrong [6] noted that these two types of glue have different values of diffusion and solubility of the water inside them. In particular, the value of the product between the diffusion coefficient and solubility is about four times higher in the case of EA 9309NA concerning the value of AF 163-2K. In addition, the soak times observed by Armstrong [6] that are required to have a strong decrease in fracture energy are respectively 300 days in the case of AF 163-2K and 22 days in the case of EA 9309NA. It is possible to deduce that the green part of the failure surfaces of the specimens made with EA 9309NA has undergone a strong degradation, which is located on the edges of the bonding area since the times used for the ageing cycles have not been sufficient to allow water to penetrate to the bulk of the bonding area. Vice versa, the specimens made with AF 163$2 \mathrm{~K}$ did not deteriorate at the end of the ageing cycles since the thirty days used for the ageing cycles are not sufficient for the water to penetrate inside the adhesive, and therefore an appreciable degradation of joint strength cannot be observed.

\section{CONCLUSIONS}

S ingle lap bonded joints in the composite material were made with two types of adhesive: film (AF 163-2K) and paste (EA 9309NA). Subsequently, the specimens were subjected to ageing cycles in air, distilled water and salt water with temperatures between $-28^{\circ} \mathrm{C}$ and $85^{\circ} \mathrm{C}$, and then tested.

Regarding the joints made with the AF 163-2K, ageing did not particularly affect the apparent shear strength.

Concerning the specimens made with the EA 9309NA, ageing has played a greater role in the apparent shear strength of the joints. In particular an increase in the apparent resistance of the joint aged in air was observed, due in part to a postcure effect of ageing on the adhesive; while in the case of joints aged in water the apparent resistance is directly proportional to the degradation of the adhesive. This has occurred because the degradation is more localized in the edges of the bonding area, which is where this type of specimen has a stress singularity: in this way, the adhesive has a lower resistance but a greater ductility where such properties are required.

\section{REFERENCES}

[1] Sorrentino, L., Turchetta, S. and Bellini, C. (2017). Analysis of carbon fibre reinforced polymers milling by diamond electroplated tool. Diam. Relat. Mater. Elsevier. 76, pp. 184-90. DOI: 10.1016/j.diamond.2017.05.005. 
[2] Sorrentino, L., Turchetta, S. and Bellini, C. (2018). A new method to reduce delaminations during drilling of FRP laminates by feed rate control. Compos. Struct. Elsevier. 186, pp. 154-64. DOI: 10.1016/j.compstruct.2017.12.005.

[3] Tucker, W. C. and Brown, R. (1989). Blister Formation on Graphite/Polymer Composites Galvanically Coupled with Steel in Seawater J. Compos. Mater., 23(4) , pp. 389-95. DOI: 10.1177/002199838902300406.

[4] Bowditch, M. R. (1996). The durability of adhesive joints in the presence of water. Int. J. Adhes. Adhes. 16, pp. 73-9. DOI: 10.1016/0143-7496(96)00001-2.

[5] Armstrong, K. B. (1996). Effect of absorbed water in CFRP composites on adhesive bonding. Int. J. Adhes. Adhes. 16, pp. 21-8. DOI: 10.1016/0143-7496(96)88481-8.

[6] Armstrong, K. B. (1997). Long-term durability in water of aluminium alloy adhesive joints bonded with epoxy adhesives. Int. J. Adhes. Adhes. 17, pp. 89-105. DOI: 10.1016/S0143-7496(96)00038-3.

[7] Wylde, J. W. and Spelt, J. K. (1998). Measurement of adhesive joint fracture properties as a function of environmental degradation. Int. J. Adhes. Adhes. 18, pp. 237-46. DOI: 10.1016/S0143-7496(98)00028-1.

[8] Wilken, R., Fladung, T., Schiffels, P., Diekhoff, S. and Henneman, O.-D. (2005). Interfacial Diffusion of Water in Epoxy-Based Adhesive Joints. Adhes. '05.

[9] Odegard, G. M. and Bandyopadhyay, A. (2011). Physical aging of epoxy polymers and their composites. J. Polym. Sci. Part B Polym. Phys. 49, pp. 1695-716. DOI: 10.1002/polb.22384.

[10] Zhou, J. and Lucas, J. P. (1995). The effects of a water environment on anomalous absorption behavior in graphite/epoxy composites. Compos. Sci. Technol. 53, pp. 57-64. DOI: 10.1016/0266-3538(94)00078-6.

[11] Zanni-Deffarges, M. P. and Shanahan, M. E. R. (1995). Diffusion of water into an epoxy adhesive: comparison between bulk behaviour and adhesive joints. Int. J. Adhes. Adhes. 15, pp. 137-42. DOI: 10.1016/0143-7496(95)91624-F.

[12] McConnell, B. K. and Pethrick, R. A. (2010). A dielectric study of hydrolytic ageing and the effects of periodic freezing in carbon fibre reinforced plastic jointed structures. Int. J. Adhes. Adhes. Elsevier. 30, pp. 214-24. DOI: 10.1016/j.ijadhadh.2010.01.003.

[13] Sorrentino, L., Polini, W., Bellini, C. and Parodo, G. (2018). Surface treatment of CFRP: influence on single lap joint performances. Accepted by Int. J. Adhes. Adhes.

[14] Chadegani, A. and Batra, R. C. (2011). Analysis of adhesive-bonded single-lap joint with an interfacial crack and a void. Int. J. Adhes. Adhes. Elsevier. 31, pp. 455-65. DOI: 10.1016/j.ijadhadh.2011.02.006.

[15] Kumar, R. V., Bhat, M. and Murthy, C. (2013). Experimental analysis of composite single-lap joints using digital image correlation and comparison with theoretical models. J. Reinf. Plast. Compos. 32, pp. 1858-76. DOI: $10.1177 / 0731684413500859$.

[16] da Silva, L. F. M., Carbas, R. J. C., Critchlow, G. W., Figueiredo, M. A. V. and Brown, K. (2009). Effect of material, geometry, surface treatment and environment on the shear strength of single lap joints. Int. J. Adhes. Adhes. 29, pp. 621-32. DOI: 10.1016/j.ijadhadh.2009.02.012. 